\title{
Applying DMAIC Methodology to Reduce Defects of Sewing Section in RMG: A Case Study
}

\author{
Dewan Maisha Zaman*, Nusrat Hossain Zerin \\ Department of Industrial Engineering and Management (IEM), Khulna University of Engineering \& Technology (KUET), \\ Khulna, Bangladesh \\ Email: *dewanmaisha23@gmail.com, nusrathossain.zerin@gmail.com
}

How to cite this paper: Zaman, D.M. and Zerin, N.H. (2017) Applying DMAIC Methodology to Reduce Defects of Sewing Section in RMG: A Case Study. American Journal of Industrial and Business Management, 7, 1320-1329.

https://doi.org/10.4236/ajibm.2017.712093

Received: November 2, 2017

Accepted: December 17, 2017

Published: December 20, 2017

Copyright $\odot 2017$ by authors and Scientific Research Publishing Inc. This work is licensed under the Creative Commons Attribution International License (CC BY 4.0).

http://creativecommons.org/licenses/by/4.0/

\begin{abstract}
Global competition, crying off profit margin, customer requirement for high quality product at near to the ground cost and other economic factors set in motion the manufacturer to reduce their production cost without concession of quality in order to stand up in business area. Defect or wastages reduction is the initial step to reduce production cost as well as improve the quality. Higher quality comes with the reduced cycle time by reducing alternation. Apprehensive this issue, this work walks around the use of DMAIC methodology of six sigma to lessen the defect rate in sewing section of FCI (BD) LTD. Throughout five phases of DMAIC methodology, named Define, Measure, Analyze, Improve and Control, this approach minimizes defects analytically. In different phases, different types of six sigma tools were exercised. Pareto analysis was acted to identify the top defects and root causes of those defects were sensed. These were done for Ladies' tops and trousers. Brainstorming and literature review helped to endow with some potential solutions to overcome the problem. With the remedial action and implementation in pilot run, the result found is very noteworthy. The defect percentage has been reduced from 11.67 to 9.672 and as a result, the sigma level has been upgraded from 2.69 to 2.8 .
\end{abstract}

\section{Keywords}

DMAIC, Sewing Defects, Six Sigma, Sigma Level

\section{Introduction and Literature Review}

In Bangladesh economy, RMG sector plays a vital role. From the last decade, RMG sector becomes popular in Bangladesh and it contributes to the national economy in considerable rate. It is necessary to focus on quality control of gar- 
ment industry [1] [2] [3]. Cho \& Kang (2001) showed that quality control in the garment industry is a big challenge for existing and it maintained from the initial stage to the stage of final finished garment [4]. In this industry, product quality can be calculated by different kind of scale. These are quality and standard of fibers, fabric construction, yarn, surface designs, color fastness and the final finished garment products [5]. Number of defected occurrence and percentage of defected product are very common way to calculate product quality.

This research has shown that the major departments of a garment manufacturing industry are cutting section, sewing section, finishing section. After finishing of the cutting operation garments components, all the garments parts are joined and sewn as sequentially. In this research, defects of sewing operations for ladies' tops and trousers are discussed. Rahman \& Amin and Talapatra \& Rahman (2016) have mentioned that defect is the common term in the garment industry. Defect is the loss of time, cost and raw material [6] [7]. So, it is a burning question for manufacturer about how to reduce defects. This research has used DMAIC methodology to reduce defects of RMG that is used which is a problem solving of Six Sigma. The Six Sigma is a philosophy that is used to reduce defects. Nupur, Gandhi, Solanki \& Jha (2018) implemented six sigma in cutting process of apparel industry where (DMAIC) approach has been followed to solve the underlying problem of reducing defects and improving sigma level through continuous improvement process [8]. Nagi \& Altaraz (2017) also used six sigma DMAIC approach to implement lean tools and facilities layout techniques to reduce the occurrence of different types of nonconformities in the carpeting process [9].

The DMAIC method follows a conductive five-step: Define, Measure, Analyze, Improve and Control necessary to obtain reliable results. According to Brundage, Kulvatunyou, Ademujimi \& Rakshith (2017), the DMAIC approach of Six Sigma works as a filter to pass from a complex problem with many uncontrolled variables to a situation where quality is controlled [10].

This research has identified all the defects in the sewing department of FCI (BD) LTD and applies DMAIC methodology to reduce the defects and this analysis is arranged by research methodology in Section 2 by the following steps: Define, Measure, Analyze, Improve and Control Phase and Conclusion is in Section 3.

\section{Research Methodology}

For garment item, i.e. ladies' tops and trousers, data sheets were collected for the length of one month (January). The end line quality inspectors provided the data sheets from their record books from the production lines of the sewing section of FCI (BD) LTD when we visited the garments factory. 15,472 ladies' tops and trousers were examined and we found 1806 defective pieces. Our main purpose was to identify the top most defects, the root cause of the defects, give some suggestions to reduce the percent of defects and improve sigma level. DMAIC 
methodology is used for this purpose. It can be illustrated with the following.

Define: problem selection and benefit analysis. Identifying and mapping relevant processes, identifying stakeholders, prioritizing customer needs \& making a business case for the project.

Measure: translation of the problem into a measurable form, and measurement of the current situation.

Analyze: identification of influence factors and causes, identifying potential influence factors \& selecting the vital few influence factors.

Improve: design and implementation of adjustments to the process to improve the performance \& conduct pilot test of improvement actions.

Control: empirical verification of the project's results and adjustment of the process management and control system in order that improvements are sustainable, the new process capability \& implement control plans.

\subsection{Define Phase}

The purpose of this phase is to make the defects clear and define the problems. The goal of the project also should be defined very well through this phase and finally here come the processes. Before works begin we must know about all relevant elements of a process improvement. SIPOC (suppliers, inputs, process, outputs, and customers) diagram is the tool to show the process map about this information [11].

Rahman \& Amin (2016) identified the problem statement in apparel industries quality is achieved when the defects of the products are decreased [6]. The manufacturers are trying to reduce defects. In Bangladesh garment factory face high rate of rejections due to defects. For this reason they can't meet quality standards. This also increases the number of rework, scrap cost, delay of delivery due to rework [12].

The ultimate goal is to minimize the percentage of defects which results in minimize the production cost, improve quality, reduce wastes and enhance sigma level. SIPOC is the quality of a process that is evaluated by the output of the process. Table 1 shows the SIPOC flow of the FCI (BD) LTD.

Table 1. SIPOC diagram for ladies' tops \& trousers.

\begin{tabular}{|c|c|c|c|c|}
\hline Suppliers & Inputs & Process & Outputs & Customers \\
\hline \multirow{7}{*}{$\begin{array}{l}\text { Alex Fabrics Ltd. } \\
\text { Fabian Group }\end{array}$} & Unstitched cloth & Sampling & \multirow{7}{*}{$\begin{array}{l}\text { Ladies tops } \\
\text { Trousers }\end{array}$} & \multirow{7}{*}{ NyGard } \\
\hline & Machinery & Cutting & & \\
\hline & Thread & Sewing & & \\
\hline & Needles & Washing & & \\
\hline & Button & Ironing & & \\
\hline & Zipper & Finishing & & \\
\hline & Label & Packaging & & \\
\hline
\end{tabular}




\subsection{Measure Phase}

Some of the products are executive ladies' tops and trousers are inspected for defects since this was the critical product for the company as they had lot of demand and the profit margin for these particular products are high. Here the percent of defectives is found 10.30. Defect per opportunity (DPO) is 0.1167 and defect per million opportunities is 116,727 . The sigma level is 2.69 . Table 2 shows the outcome.

\subsection{Analyze Phase}

The main goal of the analyze phase is to go through the data to find out the top most defects which are reoccurring as well as the root causes of the problems and seek improvement opportunities. The percentage of defects occurrence has been integrated in Table 3 and also shown in Figure 1.

Brainstorming: It is one of the major problem solving tools. The purpose of this step is to identify, validate and select the root cause for removal. We have analyzed the causes of those defects and constructed Cause-Effect diagrams which are shown in Figure 2.

Table 2. Calculation of DPMO \& six sigma.

\begin{tabular}{cc}
\hline Total checked items & 15,472 \\
No of defectives & 1806 \\
\% Defectives & 11.67 \\
DPU & 0.1167 \\
DPMO & 116,727 \\
Sigma level & 2.69 \\
\hline
\end{tabular}

Table 3. Details of percentage defects occurrence.

\begin{tabular}{cccc}
\hline Defects & Total Occurrences & $\begin{array}{c}\text { Percentage (\%) } \\
\text { of occurrences }\end{array}$ & $\begin{array}{c}\text { Occurrences percentage (\%) } \\
\text { cumulative }\end{array}$ \\
\hline Puckering & 361 & 20 & 20 \\
Visible stitch & 326 & 18 & 38 \\
Out of shape & 307 & 17 & 55 \\
Skip stitch & 199 & 11 & 66 \\
Uneven stitch & 163 & 9 & 75 \\
Broken stitch & 144 & 8 & 83 \\
Raw edge & 90 & 5 & 88 \\
Uncut thread & 90 & 5 & 93 \\
Length stitch & 72 & 4 & 97 \\
Down stitch & 54 & 3 & 100 \\
\hline
\end{tabular}




\section{Pareto Chart for Defects}

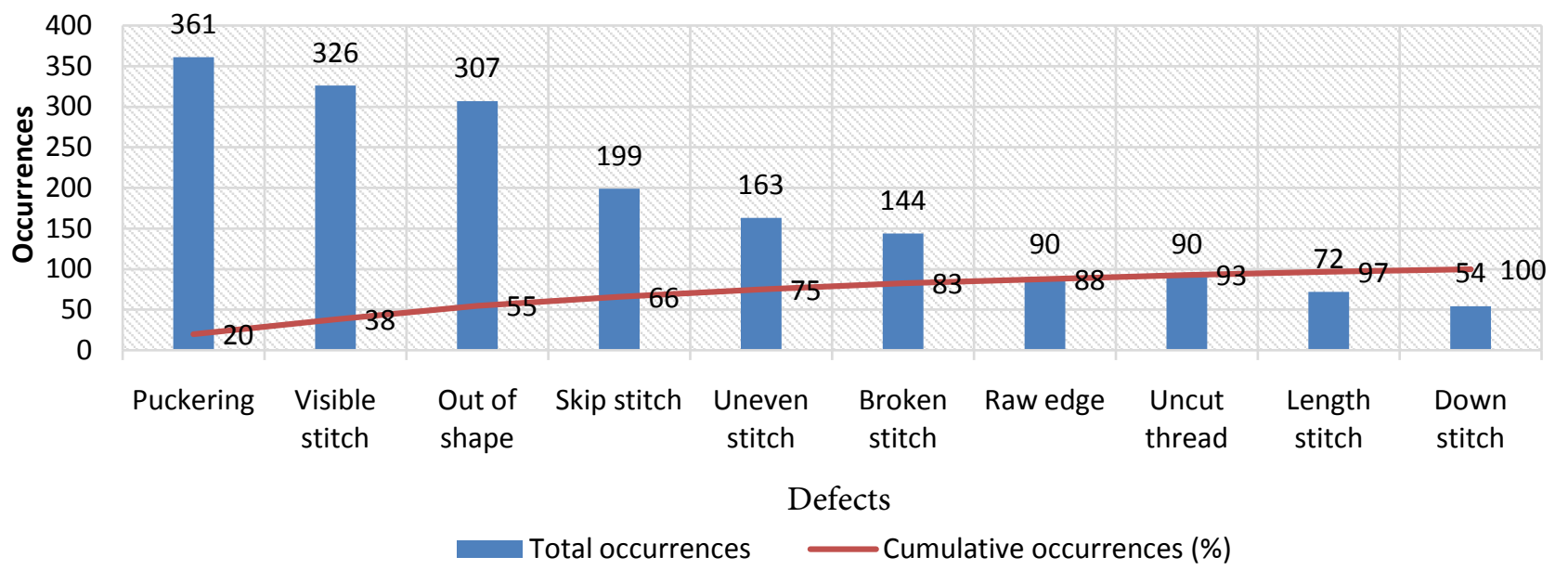

Figure 1. Pareto chart for defects.
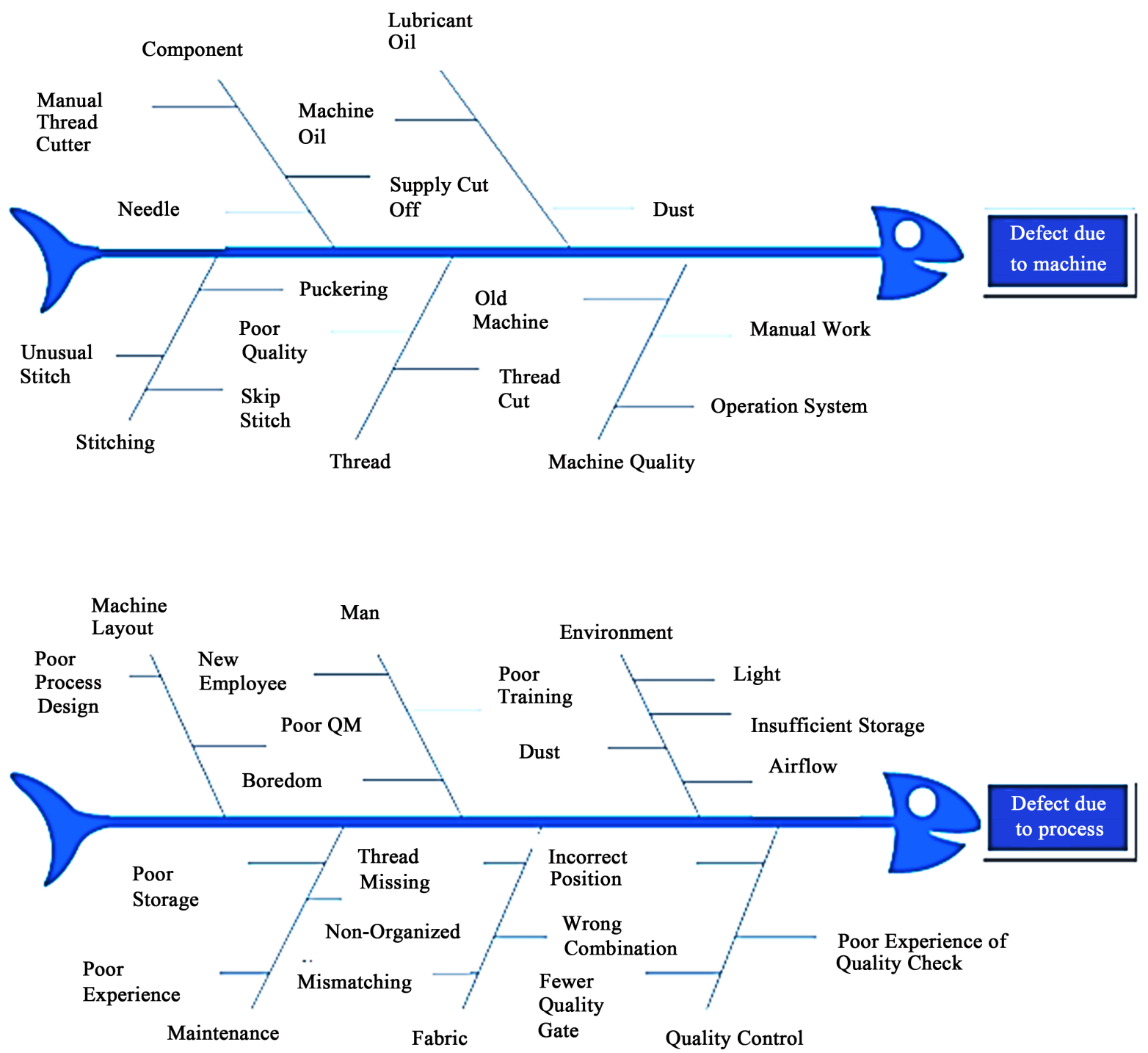

Figure 2. Cause-Effect diagram for all defects due to machine \& process. 


\subsection{Improve Phase}

The purpose of this step is to identify, test and implement a solution to the problems in part or in whole. Root causes of different types of defects have been identified and the solutions of these causes have been provided that is shown in this Table 4.

Implementation: The implementation was done into one of their pilot sewing line and details are listed in the Table 5 and Table 6. DPMO and Sigma Level were calculated and reported in Table 7.

\subsection{Control Phase}

It is possible to reduce by management of an industry the overall occurrence frequency by following some preventive ways by finding out the actual reasons.

Table 4. List of potential root causes and their solutions.

\begin{tabular}{|c|c|c|}
\hline Defect name and place & Potential root causes & Solutions \\
\hline \multirow{4}{*}{ 1) Puckering at Side Seam } & \multirow{2}{*}{ Parts handling method } & Follow the guide properly, reduce speed at shape changing area \\
\hline & & Hold both parts in asymmetric \\
\hline & Thread tension mismatched & Readjust thread tension \\
\hline & There is no mark to hold the parts properly & Put cut mark at edge during cutting the panel \\
\hline \multirow{3}{*}{ 2) Raw edge at side seam } & Parts handling method & Follow the guide properly, reduce speed at shape changing area \\
\hline & & Hold both parts in asymmetric \\
\hline & Excessive Speed & Don't exceed the speed limit 4500rpm \\
\hline \multirow{2}{*}{$\begin{array}{l}\text { 3) Waist band mouth } \\
\text { out of shape }\end{array}$} & Mouth close wrong & Straight sewing at mouth close bottom line \\
\hline & Waist band top stitch inclined & Use the shape folder for waist band top stitch \\
\hline \multirow{2}{*}{$\begin{array}{l}\text { 4) Uneven stitch at } \\
\text { back pocket top stitch }\end{array}$} & \multirow{2}{*}{ Stitch corner round shaped } & Use split bar DNLS machine for ease of operating \\
\hline & & Don't stress the pocket corner during stitching \\
\hline \multirow{3}{*}{$\begin{array}{l}\text { 5) Uncut thread at } \\
\text { loop tack }\end{array}$} & Wiper stopped & Never stop wiper \\
\hline & Stitch continued over the space & Stop stitch at the parts end \\
\hline & Bobbin thread loose & Adjust the bobbin thread \\
\hline \multirow{2}{*}{$\begin{array}{l}\text { 6) Broken stitch at } \\
\text { cross point }\end{array}$} & Stitch cut during excess thread cutting. & Cut thread end carefully \\
\hline & Use of air line during inseam join operation & Stop using air blowing if avoidable \\
\hline \multirow{4}{*}{$\begin{array}{l}\text { 7) Down stitch at waist } \\
\text { band top stitch }\end{array}$} & Waist band attach wrong & Follow block pressing mark \\
\hline & Waist band width measurement wrong & Keep the allowance same during waist band center tack \\
\hline & Cut panel width shortage & Follow marker line properly to avoid cutting mistake \\
\hline & Allowance not even at waist band attach & Keep the allowance even and follow the gauge properly \\
\hline \multirow{3}{*}{$\begin{array}{l}\text { 8) Visible stitch at } \\
\text { waist top stitch }\end{array}$} & Waist band attach wrong & Follow block pressing mark \\
\hline & Waist band width measurement wrong & Keep the allowance same during waist band center tack \\
\hline & Cut panel width shortage & Follow marker line properly to avoid cutting mistake \\
\hline \multirow{2}{*}{ 9) Length uneven } & Allowance not even at waist band attach & Keep the allowance even and follow the gauge properly \\
\hline & Size mistake & Use single piece material in sewing line to avoid size mixing up \\
\hline
\end{tabular}


Table 5. Defects after implementation of DMAIC.

\begin{tabular}{cccc}
\hline Date & Checked item & Good item & Defective item \\
\hline Feb 1 & 431 & 397 & 34 \\
Feb 2 & 570 & 411 & 159 \\
Feb 4 & 805 & 730 & 75 \\
Feb 5 & 843 & 791 & 52 \\
Feb 6 & 743 & 658 & 85 \\
Feb 7 & 887 & 826 & 61 \\
Feb 8 & 832 & 801 & 31 \\
Total & 5111 & 4614 & 497 \\
\hline
\end{tabular}

Table 6. Total defectives in ladies' tops and trousers after inspection.

\begin{tabular}{cccc}
\hline Defects & Total Occurrences & \% of occurrences & \% cumulative \\
\hline Puckering & 99 & 20 & 20 \\
Visible stitch & 89 & 18 & 38 \\
Out of shape & 85 & 17 & 55 \\
Skip stitch & 55 & 11 & 66 \\
Uneven stitch & 45 & 9 & 75 \\
Broken stitch & 40 & 8 & 83 \\
Raw edge & 25 & 5 & 88 \\
Uncut thread & 25 & 5 & 93 \\
Length uneven stitch & 20 & 4 & 97 \\
Down stitch & 14 & 3 & 100 \\
\hline
\end{tabular}

Table 7. Calculation of DPMO \& Six Sigma (after implementation of DMAIC).

\begin{tabular}{cc}
\hline Total checked items & 5111 \\
No of defectives & 497 \\
\% Defectives & 9.72 \\
DPU & 0.0972 \\
DPMO & 97241 \\
Sigma level & 2.8 \\
\hline
\end{tabular}

In this research, one preventive way awareness is used to investigate the result of frequency of defective occurrences. For this purpose awareness has been raised among all the employees, operators even among all the stakeholders of an industry. This awareness is based on how occurrences create and what are the responsibilities on them to minimize the daily percentage of occurrences. Thomas, Barton \& Chuke-Okafor (2008), De Mast (2004), George \& George (2003), Hahn, Hill, Hoerl \& Zinkgraf (1999), Husband \& Mandal (1999), Munna, Rah- 
man \& Roney (2015), Jostes \& Helms (1994) have used different lean tools i.e., $5 \mathrm{~S}$ implementation, value stream mapping (VSM), systems redesign, application of TPM to control the occurrences frequency [13]-[19]. This research has tried to implement the safety awareness that involves: 1) awareness in setting the needle with the machine 2) awareness in gripping the fabrics for long stitch (more than $10 \mathrm{~cm}$ ) 3) awareness by showing the video of standard operation for the unskilled operator and 4) awareness among the management to provide the automated machine rather than manually operated machine and observed for 10 days in line no. 17 for the defect of skip stitch, uneven stitch and broken stitch and finally this research has found that the daily defect percentage has decreased day by day after creating the awareness that is showed in the following Figure 3 and this results in one of the solution to enhance productivity.

\section{Conclusion}

The aim of this research is to reduce the defect of products and to improve quality. To minimize the defects of garment products DMAIC methodology has been used. In this method, at first problems were identified. We have been focused on sewing section and found out sewing defects. Pareto chart is used to show sewing defects for experimental lot. The percentage of defects from total product is also calculated. Define phase shows that defected piece is 1806 in 15,472 pieces. The percentage of defect was $11.67 \%$. The range is not in tolerable range. For given solution, control phase shows that defect percentage is reduced to $9.72 \%$. To justify the given solution, sigma level is used. In the past, sigma level was 2.69. After Improve phase, it has been upgraded to 2.8. This research has focused some preventive solutions from other researches and also showed that creation of awareness among the stakeholders of a garments industry has decreased the occurrences in a sewing line day by day. This will create a positive effect on the management and will also help to minimize the defective percentage (\%) in a

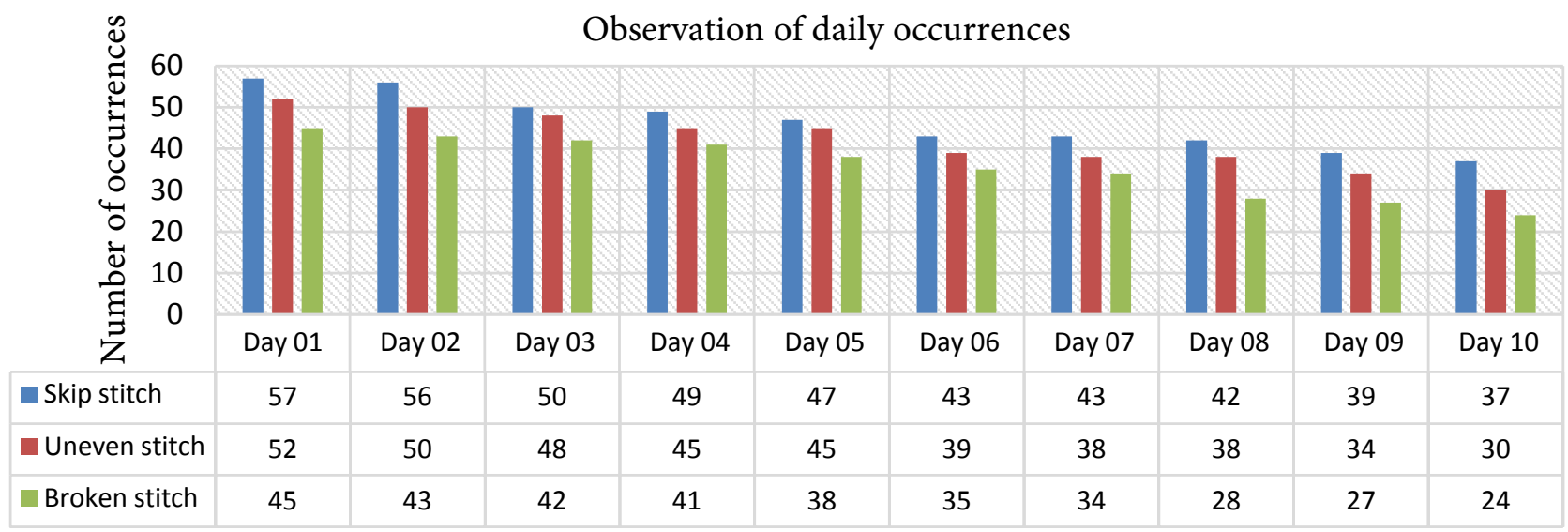

Observation days

- Skip stitch $\quad$ Uneven stitch Broken stitch

Figure 3. Observation of defective percentage (\%) control. 
sewing line of a garment industry. The limitations of this study are that: it was concentrated only on one garment industry and only for sewing section, and only one sewing line was focused, and calculation had been done for two products. But the significance of this research is that this study can help in minimizing the other sections in garments industry. Other researchers can also use this procedure to reduce defect rate in other manufacturing industries. Finally, reduction of defect rate improves quality and apparently, improvement of quality will give a positive impact in RMG sector.

\section{References}

[1] Lee, C.K.H., Choy, K.L., Ho, G.T., Chin, K.S., Law, K.M.Y. and Tse, Y.K. (2013) A Hybrid OLAP-Association Rule Mining Based Quality Management System for Extracting Defect Patterns in the Garment Industry. Expert Systems with Applications, 40, 2435-2446. https://doi.org/10.1016/j.eswa.2012.10.057

[2] Mottaleb, K.A. and Sonobe, T. (2011) An Inquiry into the Rapid Growth of the Garment Industry in Bangladesh. Economic Development and Cultural Change, 60, 67-89. https://doi.org/10.1086/661218

[3] Knutsen, H.M. (2004) Industrial Development in Buyer-Driven Networks: The Garment Industry in Vietnam and Sri Lanka. Journal of Economic Geography, 4, 545-564. https://doi.org/10.1093/jnlecg/lbh032

[4] Cho, J. and Kang, J. (2001) Benefits and Challenges of Global Sourcing: Perceptions of US Apparel Retail Firms. International Marketing Review, 18, 542-561. https://doi.org/10.1108/EUM0000000006045

[5] Eberle, H., Hermeling, H., Hornberger, M., Kilgus, R., Menzer, D. and Ring, W. (2004) Clothing Technology. Beuth-Verlag GmbH, Berlin.

[6] Rahman, M.H. and Al Amin, M. (2016) An Empirical Analysis of the Effective Factors of the Production Efficiency in the Garments Sector of Bangladesh. European Journal of Advances in Engineering and Technology, 3, 30-36.

[7] Talapatra, S. and Rahman, M.H. (2016) Safety Awareness and Worker's Health Hazards in the Garments Sector of Bangladesh. European Journal of Advances in Engineering and Technology, 3, 44-49.

[8] Nupur, R., Gandhi, K., Solanki, A. and Jha, P.C. (2018) Six Sigma Implementation in Cutting Process of Apparel Industry. In: Quality, IT and Business Operations, Springer, Singapore, 279-295. https://doi.org/10.1007/978-981-10-5577-5_22

[9] Nagi, A. and Altarazi, S. (2017) Integration of Value Stream Map and Strategic Layout Planning into DMAIC Approach to Improve Carpeting Process. Journal of Industrial Engineering and Management, 10, 74. https://doi.org/10.3926/jiem.2040

[10] Brundage, M.P., Kulvatunyou, B., Ademujimi, T. and Rakshith, B. (2017) Smart Manufacturing through a Framework for a Knowledge-Based Diagnosis System. In: ASME 201712 th International Manufacturing Science and Engineering Conference Collocated with the JSMEIASME, 6th International Conference on Materials and Processing, American Society of Mechanical Engineers, V003T04A012V003T04A012.

[11] Mehta, A., Eilers, L.F., Campbell, A.M., Ramirez, D.W. and Godambe, S.A. (2017) Using the PRISM Model to Drive Quality Improvement in the Emergency Department. Clinical Pediatric Emergency Medicine, 18, 103-114.

https://doi.org/10.1016/j.cpem.2017.04.002 
[12] Chiu, Y., Lin, H., Wu, M. and Chiu, S. (2018) Alternative Fabrication Scheme to Study Effects of Rework of Nonconforming Products and Delayed Differentiation on a Multiproduct Supply-Chain System. International Journal of Industrial Engineering Computations, 9, 235-248. https://doi.org/10.5267/j.ijiec.2017.6.001

[13] Thomas, A., Barton, R. and Chuke-Okafor, C. (2008) Applying Lean Six Sigma in a Small Engineering Company-A Model for Change. Journal of Manufacturing Technology Management, 20, 113-129. https://doi.org/10.1108/17410380910925433

[14] De Mast, J. (2004) A Methodological Comparison of Three Strategies for Quality Improvement. International Journal of Quality \& Reliability Management, 21, 198-213. https://doi.org/10.1108/02656710410516989

[15] George, M.L. and George, M. (2003) Lean Six Sigma for Service. McGraw-Hill, New York, 273.

[16] Hahn, G.J., Hill, W.J., Hoerl, R.W. and Zinkgraf, S.A. (1999) The Impact of Six Sigma Improvement-A Glimpse into the Future of Statistics. The American Statistician, 53, 208-215.

[17] Husband, S. and Mandal, P. (1999) A Conceptual Model for Quality Integrated Management in Small and Medium Size Enterprises. International Journal of Quality \& Reliability Management, 16, 699-713. https://doi.org/10.1108/02656719910286215

[18] Munna, M.M., Rahman, M.H. and Roney, M.F.S. (2015) Comparative Analysis for Multicriteria Inventory Classification of Unilever Brothers Ltd. Using AHP and Fuzzy AHP Models. International Journal of Mechanical Engineering \& Technolo$g y, 2,377-382$.

[19] Jostes, R.S. and Helms, M.M. (1994) Total Productive Maintenance and Its Link to Total Quality Management. Work Study, 43, 18-20. https://doi.org/10.1108/EUM0000000004012

\section{Nomenclature}

\begin{tabular}{ccc}
\hline Symbol & Meaning & Unit \\
\hline DPU & Defect Per Unit & Dimensionless \\
DPMO & Defect Per Million Opportunities & Dimensionless \\
\hline
\end{tabular}

